This item was submitted to Loughborough's Research Repository by the author.

Items in Figshare are protected by copyright, with all rights reserved, unless otherwise indicated.

\title{
Credit derivatives and the default risk of large complex financial institutions
}

PLEASE CITE THE PUBLISHED VERSION

http://dx.doi.org/10.1007/s10693-011-0121-z

\section{PUBLISHER}

(c) Springer Science+Business Media, LLC

\section{VERSION}

AM (Accepted Manuscript)

\section{PUBLISHER STATEMENT}

This work is made available according to the conditions of the Creative Commons Attribution-NonCommercialNoDerivatives 4.0 International (CC BY-NC-ND 4.0) licence. Full details of this licence are available at: https://creativecommons.org/licenses/by-nc-nd/4.0/

\section{LICENCE}

CC BY-NC-ND 4.0

\section{REPOSITORY RECORD}

Calice, Giovanni, Christos loannidis, and Julian M. Williams. 2019. "Credit Derivatives and the Default Risk of Large Complex Financial Institutions”. figshare. https://hdl.handle.net/2134/24213. 


\title{
Credit Derivatives and the Default Risk of Large Complex Financial Institutions
}

\author{
Giovanni Calice • Christos Ioannidis • \\ Julian Williams
}

the date of receipt and acceptance should be inserted later

\begin{abstract}
This paper proposes and implements a multivariate model of the coevolution of the first and second moments of two broad credit default swap indices and the equity prices of sixteen large complex financial institutions. We use this empirical model to build a bank default risk model, in the vein of the classic Merton-type, which utilises a multi-equation framework to model forward-looking measures of market and credit risk using the credit default swap (CDS) index market as a measure of the conditions of the global credit environment. In the first step, we estimate the dynamic correlations and volatilities describing the evolution of the CDS indices and the banks' equity prices and then impute the implied assets and their volatilities conditional on the evolution and volatility of equity. In the second step, we show that there is a substantial 'asset shortfall' and that substantial capital injections and/or asset insurance are required to restore the stability of our sample institutions to an acceptable level following large shocks to the aggregate level of credit risk in financial markets.
\end{abstract}

Keywords Distance to Default · Credit Derivatives · Credit Default Swap Index

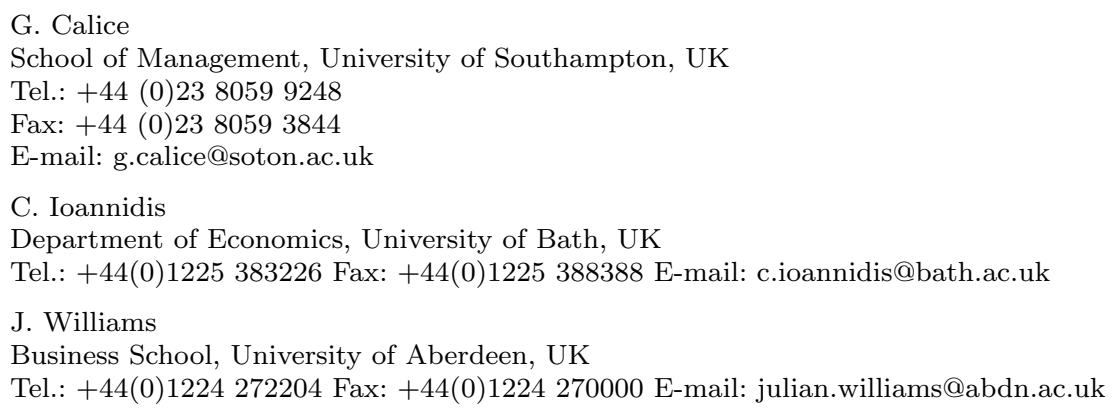




\section{Introduction}

During 2007 and 2008 the global financial system has undergone a period of unprecedented instability. The difference, however, between past financial crises and that which appears to have begun in earnest in August 2007 is the presence of the credit derivatives (CDs) market.

Whilst the causes of this crisis are fairly well recognised, the mechanism of transmission of shocks between CDs markets and the banking sector is not as well understood from an empirical perspective. In fact, the academic and practitioner literature has not yet reached firm conclusions on the financial stability implications of credit default swap (CDS) instruments. Several recent contributions such as Goldsmith-Pinkham and Yorulmazer (2010) and Behr et al. (2010) have focused on specific aspects of individual banks and their interactions with the credit and debt markets.

The objective of this paper is to shed some light on the propagation mechanism involved in banking stability by studying the credit default swap (CDS) index market during the 2003-2009 period and exploring the dynamics of the correlations of financial institutions' equity and asset values with various CDS indices as the subprime crisis of 2007 unfolded and then evolved into the global financial crisis of 2008.

We adopt a contingent claims approach, which explicitly integrates forwardlooking market information and recursive econometric techniques to track the evolution of default risk for a sample of 16 large complex financial institutions (LCFIs) and the classic distance to default (henceforth D-to-D) model for the pricing of corporate debt first established in Merton (1974a) and Merton (1974b). Since one of the most important determinants of CDS prices is the likelihood of the reference entity to default in case of a credit event, and this likelihood is tightly linked to stock market valuation, it is natural to empirically investigate the link between the stock market and CDS markets.

The paper investigates the links between the value of banks' equity and the CDS market. The basic idea is that, as banks deliberately undertake risky projects that embed counterparty risk, the value and volatility of the banks' assets will co-evolve with developments in CDS markets. Our paper makes two distinctive contributions. The first is a new approach to modelling banking fragility that explicitly incorporates the transmission of corporate credit risk from the CDS index market. Our model thus contributes to the existing literature on credit risk models and measures of systemic risk by exploring the intuition that CD premia are univariate timely indicators of information pertinent to systemic risks. While applications of the D-to-D methodology have so far mostly concentrated on the option pricing literature, we show that the Merton approach can be applied to the area of credit risk transfer (CRT).

We estimate, recursively, a vector autoregression with multivariate autoregressive conditionally heteroskedastic disturbances (VAR-MV-GARCH) model on bank equity returns and the change in value of two representative CDS indices (the North American CDX and the European iTraxx). The CDS indices are used to proxy the embedded counterparty risk present in the global econ- 
omy and act as volatility instruments in a multivariate stochastic volatility option pricing model. Utilising the volatility forecasts from Monte Carlo simulations, we obtain the forward looking empirical distribution of equity and hence asset volatilities. We subsequently compute the probability of default for each institution included in the sample.

Our second contribution is in the final part of the paper, where we impute the required 'extra assets' for each institution, based on the distribution of the volatility of their own assets, given a target probability of default, which is set by the regulator. We believe that this setting constitutes a useful predictive tool that financial regulators may wish to employ to gauge the implications for the stability of systemically important financial institutions given developments in CDS markets.

As far we are able to determine, this is the first investigation to establish a relationship between the CDX and iTraxx CDS indices and the banking sector that supports the consideration of a transmission mechanism in order to account for the potential of default risk of several global LCFIs. We adopt a working definition of banking instability as an episode in which there is a significant increase in cross-market linkages after a shock occurs in the CDS market. The existing studies measure changes in cross-market interdependencies but fall short of exploring changes in the first and second moments of CDS indices. This is the key novelty of our approach. It is important to note, however, that this formulation inevitably simplify and abstracts from reality by ignoring critical dimensions of broader system-wide financial stability assessments.

Our most important findings are twofold. First, we find that LCFIs are conditionally correlated to changes in the valuation of CDs. More specifically, we find that the sensitivity of default risk across the banking system is highly correlated with both the CDX and iTraxx index markets and that this relationship has, on average, a positive sign and changes in magnitude through time. Hence, correlations between financial institutions equity prices and the CDS index market matter. Second, our model allows us to quantify the solvency ratio for each LCFI via the overall price-discovery process in the two CDS index markets.

All our results have important implications both for the financial stability literature and for global banking regulators. The results help to quantify the correlations between of shocks from the CDS market along with their volatility to a specific metric of financial stability, namely the probability of default of LCFIs. Our approach can serve as an early warning system for supervisors to pursue closer scrutiny of a bank's risk profile, thereby prompting additional regulatory capital and enhanced supervision to discourage practices that increase systemic risk.

The remainder of the paper is organised as follows. $\S(2)$ briefly reviews the related literature. $\S(3)$ outlines the theoretical foundations of our approach. $\S(4)$ outlines our choice of LCFIs for our sample and describes the financial data used in the study. The results are presented in $\S(5)$ and $\S(6)$ concludes. 


\section{Related Literature}

To our knowledge, the closest precursor to our analysis is the research by Bystrom (2005) and Gropp et al. (2006). Bystrom (2005) finds a link between equity prices, equity return volatilities and CDS spreads for a set of data from the European iTraxx CDS indices and stock indexes and finds that CDS spreads have a strong tendency to widen when stock prices fall and vice versa. Stock price volatility is also found to be significantly correlated with CDS spreads and the spreads are found to increase (decrease) with increasing (decreasing) stock price volatility.

Longstaff (2010) finds that, during the subprime crisis of 2007, the value of asset-backed collateralized debt obligations (CDOs) (using the ABX index as proxy) had a strong predictive power for stock market returns (using the S\&P 500 and the S\&P 500 financial subindex as proxies). He demonstrates empirically that the ABX indices were signalling critical information on market distress for as much as three weeks ahead of the onset of the crisis and finds strong evidence supporting a contagion mechanism - from the ABX index to other financial markets - driven primarily by market premia and liquidity channels as opposed to the correlated-information channel.

Although the data used in the study covers the period between 2006 and 2008 and results focus only on the 2007 subprime crisis, the study constitutes a highly valuable contribution as it sheds light on the potential correlation between the ABX index market and other financial markets.

The recent and growing literature on financial innovation and financial stability is characterised by a lack of consensus on the net effect of CRT on the financial system. Duffie (2008) discusses the costs and benefits of CRT instruments for the efficiency and stability of the financial system. The argument is that, if CRT leads to a more efficient use of lender capital, then the cost of credit is lowered, presumably leading to general macroeconomic benefits such as greater long-run economic growth.

CRT may encourage excessive levels of leverage raising the amount of total credit risk in the economy to unwarranted levels, thus amplifying the effect of negative credit shocks to the system. Allen and Gale (2000) develop a model of banking and insurance and show that, with complete markets and contracts, inter-sectoral transfers are desirable. However, with incomplete markets and contracts, CRT can occur as the result of regulatory arbitrage and this can increase systemic risk.

Using a model with banking and insurance sectors, Allen and Carletti (2006) document that the transfer of risk between the banking sector and the insurance sector can lead to damaging contagion of systemic risk from the insurance to the banking sector as the CRT induces insurance companies to hold the same assets as banks. If there is a crisis in the insurance sector, insurance companies will have to sell these assets, forcing down the price, which implies the possibility of contagion of systemic risk to the banking sector since banks use these assets to hedge their idiosyncratic liquidity risk. 
Morrison (2005) shows that a market for CDs can destroy the signalling role of bank debt and lead to an overall reduction in welfare as a result. It is suggested that disclosure requirements for CDs can help offset this effect.

Baur and Joossens (2006) derive the conditions under which loan securitisation can increase the amount of systemic risks in the banking sector. They use a simple model to show how securitisation can reduce the individual banks' economic capital requirements by transferring risk to other market participants, and demonstrate that stability risks do not decrease as a result of asset securitisation. As a result, systemic risk can increase and impact on the financial system for two reasons. First, because the risks are transferred to unregulated market participants, who are obliged by the regulators to hold additional capital reserves, and second, because the risks are transferred to other banks, interbank linkages increase and subsequently augment systemic risk. A recent study by $\mathrm{Hu}$ and Black (2008) concludes that, thanks to the explosive growth in CDs, debt-holders such as banks and hedge funds have often more to gain if companies fail than if they survive. The study warns that the breakdown of the relationship between creditors and debtors, who traditionally worked together to keep solvent companies out of bankruptcy, lowers the system's ability to deal with a significant downward shift in the availability of credit.

There is also limited consensus on the relative importance of CDS and bond markets, and even less consensus on the CDS-equity markets relation. Zhu (2006) discusses the role of the CDS market in price discovery in the corporate fixed income security sector. Using a vector autoregression (VAR) framework, he finds evidence in favour of the hypothesis that the CDS market moves ahead of the bond market, thus contributing more to price discovery.

Similar to the approach adopted by Zhu (2006), Longstaff et al. (2005) find that changes in both CDS premiums and stock returns often lead changes in corporate bond yields. In the Jorion and Zhang (2007) investigation of the intra-industry credit contagion effect in the CDS market and the stock market, the CDS market is found to lead the stock market in capturing the contagion effect.

The traditional literature on the empirical applications of the Merton Model has long recognised that the D-to-D measure can be an efficient analytical predictor of individual firm's fragility. A vast number of contributions have been developed, particularly in the banking literature. Sy and Chan-Lau (2006) measure bank vulnerability in emerging markets using the D-to-D. The indicator is estimated using equity prices and balance-sheet data for 38 banks in 14 emerging market countries. They find that the D-to-D can predict a bank's credit deterioration up to nine months in advance and it may prove useful for supervisory core purposes.

Berndt et al. (2005) examine the relationship between CDS premiums and Expected Default Frequencies (EDFs). Moody's KMV EDFs are conditional probabilities of default, which are fitted non-parametrically from the historical default frequencies of other firms that have the same estimated D-to-D as the targeted firm. The D-to-D is the number of standard deviations of annual 
asset growth by which its current assets exceed a measure of book liabilities. They find that there is a positive link between 5-year EDFs and 5-year CDS premiums. However, the sample only includes North American companies from three industries. The results therefore might not be representative of the whole market.

Gropp et al. (2006) show that the D-to-D may be a particularly suitable way to measure bank risk, avoiding problems of other measures, such as subordinated debt spreads. The authors employ the Merton's model of credit risk to derive equity-based indicators for banking soundness for a sample of European banks. They find that the Merton style equity-based indicator is efficient and unbiased as a monitoring device. Furthermore, the equity-based indicator is forward looking and can warn of a crisis 12 to 18 months ahead of time. The D-to-D is able to predict banks' downgrades in developed and emerging market countries.

Lehar (2005) proposes a new method to measure and monitor banking systemic risk. The author proposes an index, based on the Merton model, which tracks the probability of observing a systemic crisis - defined as a given number of simultaneous bank defaults - in the banking sector at a given point in time. The method proposed allows regulators to keep track of the systemic risk within their banking sector on an ongoing basis. The approach permits the comparison of the risk over time as well as between countries. For a sample of North American and Japanese banks (at the time of the Asian crisis in $1997 / 98)$ the author finds evidence of a dramatic increase in the probability of a simultaneous default in the Japanese banks whilst this decreases over time for the North American banks. This type of model is applied to large complex banking groups in Berger et al. (2008)

There are several mechanisms through which the CD market may act as a conduit for the transmission of shocks between financial institutions. First as a direct consequence of holding holding these instruments on their balance sheet and their subsequent revaluation (for instance by writing protection on assets that suddenly deteriorate in quality). Second, through individual counter-party adjustments caused by sudden changes in the credit quality of other LCFIs, for instance the sudden adjustments in interbank rates after the Lehman Brothers default. Third, by changing the systemic or market wide component of credit risk (in the parlance of Longstaff (2010)) on all transactional parts of the financial system. This follows on directly from the ideas set out in Longstaff et al. (2005) who propose a triply stochastic poisson process with idiosyncratic, sectoral and market risk in the pricing model.

We attempt to capture these affects in the asset process by including broad CDS indices constructed from CDS written on corporate debt from a cross section of large US and European firms. The indices form a barometer of the level of global credit risk, which should in turn reflect the credit risk in the wider economy. These indices are combined into a multivariate model that captures at least two components of the presumed default risk structure (idiosyncratic and market wide). 


\section{Methodology}

We divide our empirical analysis into three sections. In the first section $\S \S(3.1)$, we develop a theoretical framework for calculating levels of default risk subject to a policy objective. In the second section, $\S \S(3.2)$, we outline a generalised stochastic volatility model of bank assets with multiple volatility instruments. Finally, in the third section, $\S \S(3.3)$, we define an econometric model using a vector autoregressive model with multivariate autoregressive conditionally heteroskedastic disturbances (VAR-MV-GARCH) to determine the time evolution of the joint volatilities of the equity and our benchmark CDS indices. We also extend this model to infer forward-looking simulations of the joint evolution of the asset value process and hence determine the additional asset requirements for each individual LCFI.

\subsection{Default Risk and Policy Objectives}

We use the term distance to default (D-to-D) or default risk in order to follow the generally accepted convention in the previous literature in this area as this proxy is considered a valid measure of insolvency.

Consider a policy maker setting a target default risk probability, $p^{*}$ over the time horizon $T-t$, defined as $p^{*}$, such that for any systemically important institution, $p_{i, t} \leq p^{*}$, is imposed by a regulator. The probability of default at time $t$, for the $i^{t h}$ institution, will be conditioned on both the imputed value of the assets, $V_{A, t}$ and their volatility, $\sigma_{A, t}$.

For any given systemically important financial institution suffering from financial distress, with probability of default, $p_{i, t}$, the difference in probability $p^{*}-p_{i, t}$, under the assumption of conditional normality, will correspond to the difference between the minimum D-to-D set by the regulator and the current imputed distance:

$$
\delta_{i, t}=\eta\left(p^{*}\right)-\eta\left(p_{i, t}\right)
$$

where $\eta(\cdot)$ denotes the number of standard deviations from default calculated under $p^{*}$ and $p_{i, t}$ respectively. When $\delta_{i, t}$ is negative the D-to- $\mathrm{D}$ is below a tolerable level for the regulators and an asset injection of $\gamma_{i, t}=V_{A}\left(p^{*}\right)-$ $V_{A}\left(p_{i, t}\right)$ is required to restore the institution to the acceptable level of default risk. We define $\gamma_{i, t}$ as the asset shortfall at time $t$.

Consider $V_{E}$ and $V_{L}$ as the observed value of equity and liabilities respectively at time $t$. We can treat the calculation of the banks solvency ratio as a typical option pricing model by adopting the standard approach that treats $V_{E}$ as equivalent to a European call option on assets at time $T$, a period that we impose exogenously.

Treating the value of the liabilities as fixed, the value of this call option with strike price $V_{L}$ will be dependent on the properties of the underlying stochastic process driving the value of assets, with structural parameters $\theta_{A}\left(\mu_{A}, \sigma_{A}\right)$ and the current value of these assets $V_{A, t}$

$$
V_{E, t}=C\left(t, T, V_{A, t}, V_{L, t}, \theta_{A}\right) .
$$


Because the value of the assets is uncertain, the price of the call option will be proportional to the probability of default

$$
p \propto C\left(t, T, V_{A, t}, V_{L, t}, \theta_{A}\right) .
$$

For a regulator the objective, at time $t$, is to assess whether the probability that the value of assets, $V_{A}$ at $T$, being less than the value of liabilities $V_{L}$, should not exceed $p^{*}$

$$
\int_{0}^{V_{L, T}} \Gamma\left(V_{A, T} ; t, T, V_{A, t}, \theta_{A}\right) d s \leq p^{*}
$$

where $\Gamma(\cdot)$ is the terminal probability density function at $T$ of the value of assets $V_{A, t}$.

\subsection{A Stochastic Volatility Model of Bank Assets}

We motivate our proposed relationship between the fluctuations of the banks' assets and developments in the market for CDS by considering the evolution of assets $V_{A}$ of a typical bank with liabilities $V_{L}$, conditional on developments in the CDS market.

Liabilities are fixed and are of known value and liquidity. Assets are chosen from a portfolio of risky underlying assets and hedging instruments to achieve a target level of risk exposure. The overall portfolio of assets is constructed from vectors of individual unhedged risky assets, $S(t)$, and hedging instruments, $H(t)$, such that $V_{A}(t)=\alpha^{\prime} S(t)+\beta^{\prime} H(t)$.

The vectors $\alpha$ and $\beta$ represent, respectively, weights of individual assets and hedging instruments that the bank chooses in order to target a level of exposure consistent with the target level of volatility $\sigma^{*}, V_{A}$. Counterparty risk is embedded into the hedging contracts used to control the banks' exposure. Such risk is captured by a vector of instruments representing the uncertainty surrounding the reliability of the hedging instruments' valuations.

We consider that this risk vector is driven by a $k-1$ length set of instruments $x_{i} \in\left\{x_{1}, \ldots, x_{k-1}\right\}$ which can be regarded as representing counterparty risk embedded into the hedging contracts used to control the banks' exposure. ${ }^{1}$

Combining the assets and the instruments in the second risk vector, we define the $k$ length vector $\tilde{x}(t)=\left[V_{A}(t), x^{1}(t), \ldots, x^{k-1}(t)\right]^{\prime}$ and the multivariate stochastic differential equation that denotes its time evolution as follows

$$
d \tilde{x}(t)=\mu(\tilde{x}(t) \mid \theta) d t+\sigma(\tilde{x}(t) \mid \theta) d W(t)
$$

1 Suppose you have a holding of value 100 in a single representative risky asset with volatility of $25 \%$. A portfolio of hedging instruments is constructed to reduce exposure to all but $5 \%$ of fluctuations of this risky asset. Should the terminal value of the risky asset drop by $20 \%$, then the hedging instruments should provide an in-flow of 19, leaving a loss of 1 . Let us now assume that the hedging portfolio provides a realized in-flow of 10 instead of the anticipated 19, the difference of 9 is the additional loss due to counterparty risk exposure. 
where $\mu$ is a vector/matrix function of drifts, $\sigma$ is a vector/matrix function driving volatility and $W(t)$ is a $k$ dimensional Weiner process, i.e. $W^{i}(t+h)-$ $W^{i}(t) \sim \mathcal{N}(0, h)$. Turning to the the nature of $\mu(\cdot)$ and $\sigma(\cdot)$, we proceed following the approach suggested by Williams and Ioannidis (2011) and adopt a stochastic covariance model of the form

$$
\begin{aligned}
d \tilde{x}(t) & =r(\tilde{x}(t)) d t+\Sigma^{\frac{1}{2}}(t)(\operatorname{idiag}(\tilde{x}(t)) d W(t)) \\
\Sigma_{A}(t) & =A(t) A^{\prime}(t) \\
A(t) & =i v e c h(\log a(t)) \\
d a(t) & =\lambda(a(t)) d t+\xi(a(t)) d W(t)^{\sigma}
\end{aligned}
$$

where $r(\tilde{x}(t))=\left[r V_{A}(t), \mu^{1} x^{1}(t), \ldots, \mu^{k-1} x^{k-1}(t)\right]^{\prime}$. The first term indicates that the growth of assets is based on the instantaneous risk free rate $r$ and $\left\{\mu^{1}, \ldots, \mu^{k-1}\right\}$ are the independent drifts of the instruments.

The stochastic covariance matrix $\Sigma_{A}(t)$ consists of a $\frac{1}{2} k(k+1)$ vector stochastic process $a(t)$. For simplicity, we set $\lambda$, for the covariance process to be zero and the volatility of volatility function, $\xi(\cdot)$, is considered time invariant, $a_{i}(t) \in \mathbb{R}$. Williams and Ioannidis (2011) derive the optimal number of hedging instruments for a simple stochastic covariance model to be $\frac{1}{2} k(k+1)+1$, given $k$ diagonal and $\frac{1}{2} k(k-1)$ off-diagonal processes driving the volatility component. The attractive feature of this model is that it enables the derivation of an analytic specification of a single quantity that combines all the relevant variance and covariance terms, as $\Sigma_{A}(t)$ is guaranteed to be positive-semi-definite (PSD). The evolution of $\tilde{x}(t)$ from time $t$ to $t+h$ can be represented by an instantaneous multivariate Brownian motion with covariance matrix

$$
\Sigma_{A}(t, t+h)=\int_{t}^{t+h} f\left(d W(t)^{\sigma}\right) d s
$$

where $f$ is a function that aggregates the steps in the volatility equation in 6 . The use of the ivech transformation ensures positive semi-definiteness (PSD) on any instantaneous realisation of $\Sigma_{t}$ and allows for its factorisation. Denoting $\Sigma^{1 / 2}(t)$ as a matrix square-root (we choose the Cholesky factor) of the instantaneous covariance matrix $\Sigma(t)$ and depending upon the complexity of the assumed processes driving $a$ we can establish an analytic solution to the variance of volatility density or alternatively utilise Monte Carlo simulations.

A European call option on the bank's assets would therefore be priced over the integral of the possible volatilities

$$
C\left(t, T, V_{A}, V_{L} \mid \theta\right)=\int_{0}^{\infty} \Phi\left(\sigma_{A}\right) \tilde{C}\left(t, T, V_{A}, V_{L}, \sigma_{A}\right) d s=V_{E}(t)
$$

where $V_{L}$ is the strike price, $T$ is the maturity of the call, $\tilde{C}$ denotes the Black and Scholes price of a call option with volatility $\sigma_{E}$ aggregated over all possible paths $s$ and $\Phi\left(\sigma_{A}\right)$ is the distribution function of volatilities. 
As we are unable to observe the continuous time asset process, we adopt the specification that can predict the values of the call option, i.e. the value of equity, that exhibits stochastic covariation with the evolution of our chosen volatility instruments and we incorporate this property into an econometric specification of equity. Consequently, the actual realisation of the volatility of equity results from the matrix square root of the instantaneous covariance between equity and CDS indices and not merely from the square root of the realisation of its own variance.

The opaqueness of the over the counter (OTC) market, the lack of margin/reserve requirements and the somewhat arbitrary nature of mark to market valuations of derivatives instruments, render the CDS indices a useful proxy for the level of counterparty risk in the market, thus approximating the volatility of the hedging instruments, $H(t)$. Following this rationale, the equity vector process $y(t)$ will incorporate the bank equity and representative CDS indices and their associated volatility processes $\Sigma(t)$.

\subsection{Econometric Specification}

Under the framework illustrated above, we use a vector autoregression (VAR) model, $y_{t}=Z y_{t-1}+\mu+u_{t}$, with BEKK type multivariate autoregressive conditionally heteroskedastic disturbances to define the discrete time dynamics of the mean and variance systems.

We utilise $k=2$ factors in the equity model, the returns on the CDX 5 year investment grade and iTraxx 5 year investment grade CDS indices. We use the AAA tranches for both indices, i.e. the highest level tranches in the CDS index. These indices cover the credit quality of large cross sections of named bond issuers in North America (CDX) and Europe (iTraxx), which are then equally weighted into an index. In each case we can think of these as being a barometer for the credit conditions of the 125 largest companies in these two economically important regions. An alternative approach would be to utilise factor/principal component decompositions of large cross sections of individually named CDS issuances and we intend to follow this approach in future work.

Therefore, $Z$ is the $3 \times 3$ matrix of lagged coefficients, $\mu$ is a vector of intercepts and $u_{t}$ is a disturbance process with conditional covariance matrix $\mathbb{E}_{t} u_{t} u_{t}^{\prime}=\Sigma_{t}$. Within this specification we are able to calculate the conditional volatility of equity for each bank based on the evolution and volatilities of our chosen instruments. This allows us to extract the conditional market values for assets and their volatilities. We use then these estimates for calculating the required extra assets under alternative volatility scenarios.

The vector of interest is the VAR of the equity returns and log differences of the CDX and iTraxx CDS indices, $y_{t}=\left[\Delta \log \left(V_{E, t}\right), \Delta \log \left(C D X_{t}\right)\right.$, $\left.\Delta \log \left(i \operatorname{Trax} x_{t}\right)\right]^{\prime}$. The VAR model to be estimated is given by 


$$
\left[\begin{array}{c}
\Delta \log \left(V_{E, t}\right) \\
\Delta \log \left(C D X_{t}\right) \\
\Delta \log \left(i \operatorname{Trax}_{t}\right)
\end{array}\right]=\left[\begin{array}{lll}
z_{1,1} & z_{1,2} & z_{1,3} \\
z_{2,1} & z_{2,2} & z_{2,3} \\
z_{3.1} & z_{3,2} & z_{3,3}
\end{array}\right]\left[\begin{array}{c}
\Delta \log \left(V_{E, t-1}\right) \\
\Delta \log \left(C D X_{t-1}\right) \\
\Delta \log \left(i \operatorname{Trax}_{t-1}\right)
\end{array}\right]+\left[\begin{array}{l}
\mu_{1} \\
\mu_{2} \\
\mu_{3}
\end{array}\right]+\left[\begin{array}{c}
u_{1, t} \\
u_{2, t} \\
u_{3, t}
\end{array}\right]
$$

The model disturbances $u_{t}=\left[u_{1, t}, u_{2, t}, u_{3, t}\right]^{\prime}$ are driven by a first order MVGARCH conditional covariance model

$$
\begin{aligned}
& {\left[\begin{array}{ccc}
\sigma_{1, t}^{2} & \sigma_{1,2, t} & \sigma_{1,3, t} \\
\sigma_{2,1, t} & \sigma_{2, t}^{2} & \sigma_{2,3, t} \\
\sigma_{3,1, t} & \sigma_{3,2, t} & \sigma_{3, t}^{2}
\end{array}\right]=\left[\begin{array}{ccc}
k_{1} & k_{2} & k_{3} \\
0 & k_{4} & k_{5} \\
0 & 0 & k_{6}
\end{array}\right] \cdot\left[\begin{array}{ccc}
k_{1} & k_{2} & k_{3} \\
0 & k_{4} & k_{5} \\
0 & 0 & k_{6}
\end{array}\right]^{\prime}} \\
& +\left[\begin{array}{ccc}
A_{1} & 0 & 0 \\
0 & A_{2} & 0 \\
0 & 0 & A_{3}
\end{array}\right] \cdot\left[\begin{array}{ccc}
\sigma_{1, t-1}^{2} & \sigma_{1,2, t-1} & \sigma_{1,3, t-1} \\
\sigma_{2,1, t-1} & \sigma_{2, t-1}^{2} & \sigma_{2,3, t-1} \\
\sigma_{3,1, t-1} & \sigma_{3,2, t-1} & \sigma_{3, t-1}^{2}
\end{array}\right] \cdot\left[\begin{array}{ccc}
A_{1} & 0 & 0 \\
0 & A_{2} & 0 \\
0 & 0 & A_{3}
\end{array}\right]^{\prime} \\
& +\left[\begin{array}{ccc}
B_{1} & 0 & 0 \\
0 & B_{2} & 0 \\
0 & 0 & B_{3}
\end{array}\right] \cdot\left[\begin{array}{l}
u_{1, t-1} \\
u_{2, t-1} \\
u_{3, t-1}
\end{array}\right] \cdot\left[\begin{array}{lll}
u_{1, t-1} & u_{2, t-1} & u_{3, t-1}
\end{array}\right] \cdot\left[\begin{array}{ccc}
B_{1} & 0 & 0 \\
0 & B_{2} & 0 \\
0 & 0 & B_{3}
\end{array}\right]^{\prime}
\end{aligned}
$$

which is more compactly written in matrix notation as

$$
\Sigma_{t}=K K^{\prime}+A \Sigma_{t-1} A^{\prime}+B u_{t-1} u_{t-1} B^{\prime}
$$

where $K K^{\prime}$ is the intercept in the variance equation and $A$ and $B$ are the $3 \times 3 \mathrm{ARCH}$ and GARCH autoregression coefficients, respectively. The long run covariance matrix of the VAR system disturbances takes the following form

$$
\operatorname{vec} \Sigma=(I-A \otimes A-B \otimes B)^{-1} \operatorname{vec}\left(K K^{\prime}\right)
$$

The system is estimated using maximum likelihood estimation (MLE) under the assumption of conditional multivariate normality. To calculate a bank's default risk, $\delta_{i, t}$, against the maximum acceptable probability of default, $p^{*}$, we use the estimated VAR-MV-GARCH model as follows. From the VAR-MVGARCH we calculate the conditional volatility of equity and, given the observed values of equity and liabilities, we are able to solve for the imputed value of assets and their conditional volatility (now as a function of the VAR-MVGARCH parameters), using the Merton (1974a) approach. To approximate the integral in equation 11 we generate forward looking Monte Carlo pathways for different asset volatilities and numerically derive the distribution.

In addition to standard significance tests on individual coefficients we have also conducted systematic and block restriction tests on the inclusion and exclusion of the two CDS indices in the equity mean and variance equations.

The daily volatility of equity needed, $\sigma_{E, t}$, to solve the option pricing problem is the top element of the Cholesky factorisation $\Sigma_{t}^{1 / 2}$ of the conditional covariance matrix. Recall that $u_{t}=\Sigma_{t}^{1 / 2} \epsilon_{t}$, where $\epsilon \sim \mathcal{N}\left(0, I_{3}\right)$ is a three variate vector drawn from a zero mean, uncorrelated i.i.d normal distribution with unit variance. Once the time evolution of $\sigma_{E, t}$ is known, we can use the square root sum over 252 trading days to construct a moving annualised equivalent. 
Repeating this exercise for a large number of draws forms the basis of our simulation study.

\subsection{Forward Looking Simulations}

We draw $N=100,000$, one year ( $s$ steps of 252 trading days) pathways of the $3 \times 1$ column vector $\varepsilon_{t}$

$$
\left(\tilde{y}_{t+s}, \tilde{\Sigma}_{t+s}\right) \mid \tilde{\varepsilon}_{t+(s-1)}, \ldots, \tilde{\varepsilon}_{t} ; \hat{\theta}
$$

For each pathway, we compute the annualised average volatility. ${ }^{2}$ We use $\sim$ to represent the draw and evolution from each sample path. Following Hafner (2003) who demonstrates that an MV-GARCH type process exhibits time varying multivariate fourth moments, we conduct our simulation study across the Monte Carlo paths to capture this effect.

We then sum over one forward-looking year $\tilde{\Sigma}=\sum_{s=1}^{252} \tilde{\Sigma}_{t+s} \mid \tilde{\varepsilon}_{t+(s-1)}, \ldots, \tilde{\varepsilon}_{t} ; \hat{\theta}$. Using the methodology of Merton, we then compute for each pathway the value of assets, the volatility of assets, the D-to-D and the average probability of default $\left(\tilde{V}_{A}, \tilde{\sigma}_{A}, \tilde{\eta}, \tilde{p}\right)$.

We then weight each of these pathways by $1 / N$ and sort them via the pathway average asset volatility. We exclude the top and bottom $2.5 \%$ of the simulated asset volatilities and stratify the rest into percentiles, ordered from low to high volatility level. For expositional simplicity, we choose seven stratifications. For each of these volatility percentiles, $\sigma_{A}^{i \in 1, \ldots, 10}$, we then derive the asset volatilities and compute the D-to-D for a variety of asset levels starting with the current implied asset value $\hat{V}_{A, t}$. We obtain the current asset value by deriving a mean of the asset values computed over the three trading months (66 days) prior to April 29, 2009.

By constructing an upward sloping curve relating the extra required assets $\Delta V_{A}$ against the $\mathrm{D}$-to-D, for the $i^{t h}$ volatility percentiles, $\eta^{*} \mid \hat{V}_{A}+\Delta V_{A} ; \sigma_{A}^{i}$, we calculate the increase in assets necessary to re-establish adequate buffers for each bank.

\section{Data}

Our data set consists of sixteen LCFIs and two broad investment grade CDS indices. The sample covers the period from October 20, 2003 to April 29, 2009, a total of 1,462 trading days. The chosen LCFIs consist of eight US based institutions, three UK banks, two French banks, one German bank and two Swiss banks. The Bank of England Financial Stability Review (2001), based on the analysis undertaken in Hawkesby et al. (2003) sets out classification criteria for LCFIs. In Wagner and Marsh (2006), more empirical evidence is

2 The variance-covariance matrices over all the paths will be centered around $\hat{\Sigma}$. 
provided to illustrate the importance of these 16 LCFIs to the global financial system.

It is not only an institution's size that matters for its systemic importance its interconnectedness and involvement in a wide variety of financial markets is also of significance. More specifically, the Wagner and Marsh (2006) inclusion criteria target the top ten institutions, worldwide, for equity bookrunners, bond bookrunners, syndicated loan bookrunners, FX revenues and holders of custody assets.

To join the group of LCFIs studied, a financial institution must feature in at least two of these six global rankings. We base our classification on the 2003 rankings so that all the systemically important financial institutions prior to the 2007 financial crisis are included. These institutions are systemically important as the fallout from a bank failure can cause destabilising effects for the world financial system.

These financial institutions (labels/mnemonics/series types used in the tables are in parentheses) are ABN Amro/Royal Bank of Scotland (RBS), Bank of America (BOA), Barclays (BARC), BNP Paribas (BNP), Citigroup (CITI), Credit Suisse (CS), Deutsche Bank (DB), Goldman Sachs (GS), HSBC Holdings (HSBC), JP Morgan (JPM), Lehman Brothers (LB), Merrill Lynch (ML), Morgan Stanley (MS), Société Générale (SG) and UBS Bank Corp. (UBS). In addition, we consider Bear Stearns (BS), given its crucial role as market-maker in the global CD market. In general, we adopt the criteria to sort the institutions by country, US, UK, Germany/Switzerland and France.

The CDX (CDX) IG and iTraxx (ITRAXX) IG CDS indices are broad investment-grade barometers of corporate credit risk and preliminary studies suggest that these offer a reasonable benchmark of the corporate credit environment. All data is obtained from Thomson Reuters Datastream. Liabilities are reported on a quarterly basis and are interpolated to daily frequency using piecewise cubic splines. The equity values of the LCFIs utilised in the VARMV-GARCH model are dividend adjusted. The market capitalization values are computed from the product of the number of shares (NOSH), the closing equity price (PC) and the index adjustment factor (AF). The descriptive statistics for all the series used in estimating the VAR-MV-GARCH models are presented in Table 1.

\section{Results and Analysis}

The VAR-MV-GARCH models presented in equations 12 to 14 in $\S \S(3.3)$ are estimated using a 252 day (one trading year) rolling window over the chosen sample period using maximum likelihood estimation, under the assumption of conditional multivariate normality, using the sample from October 20, 2003 to January 1, 2005 as a 'burning-in' period. In addition, we estimate the model over the January 1, 2005 to April 29, 2009 sample as a comparator. For the final one year period to April 29, 2009 we use a forecast breakdown approach in the spirit of Diebold and Mariano (1995) and further developed in Giacomini and 


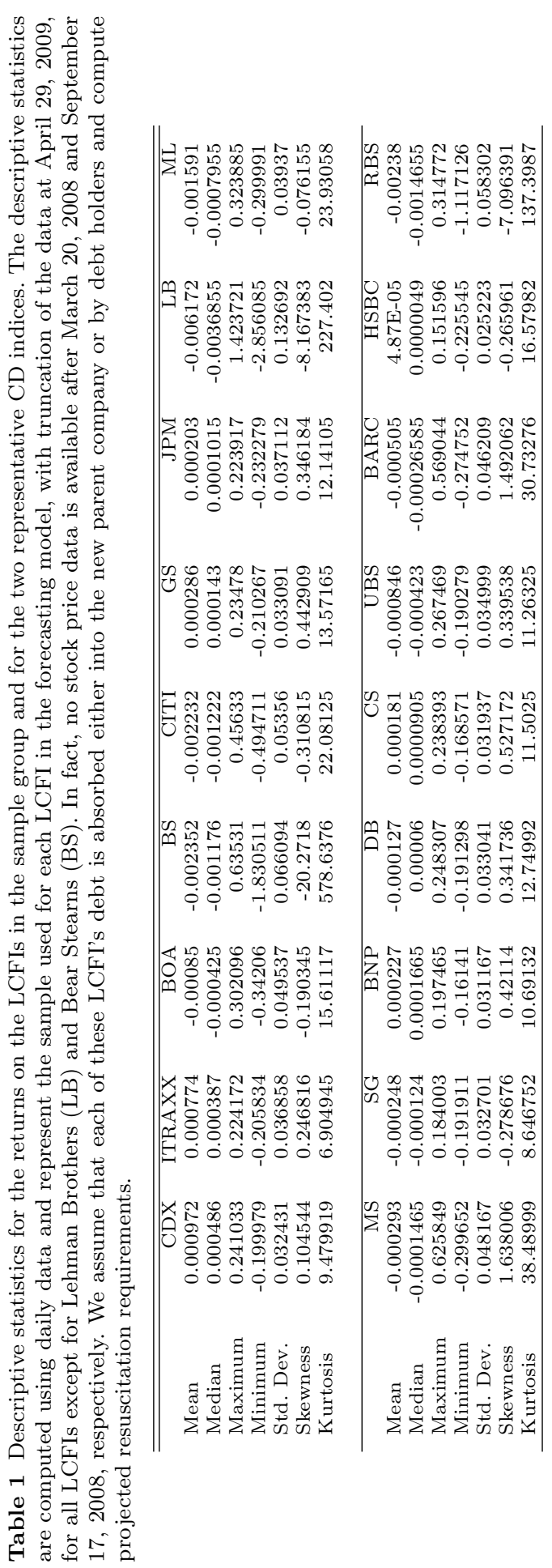


Rossi (2009) to test between the long run (whole sample estimated model), and the short run (rolling window model); this is labelled the 'best' model for the year to April 29, 2009. For each LCFI in the sample, the rolling window model was strictly preferred and this is the model used in the simulation component of the study.

Tables 2 and 3 present the coefficients for the 'best' VAR-MV-GARCH model, from equations 12 to 14 . The first column presents the label of the coefficient of interest, standard errors are in brackets. For individual parameters the MV-GARCH model for each LCFI tends to have uniformly more statistically significant coefficients than the VAR. However, individual significance tests in this type of model are not always informative and, as such, we employ a block restriction test for the exclusion of variables from the system.

For the 'best' model for the year to April 29, 2009 we implement a likelihood ratio test of block exogeneity (statistical causation) in both the first and second conditional moments for LCFIs' equity with the two chosen CDS indices. The null hypothesis of the linear independence in the moments of bank equity returns for the same moments of the two indices were conclusively rejected in all cases. These results provide the supporting evidence of the conjecture, employed in this paper, that developments in these markets (CRT) are significant factors, but by no means unique, to be taken into account for conditioning the moments of equity returns.

On the basis of these parameterised models, we now proceed to acquire estimates of the 'extra assets' required as not to exceed a given probability of default under alternative volatility scenarios. In practice the US, UK and various European governments have taken various different approaches to supporting the LCFIs during the crisis. The standard intervention has been a mix of extra capital (via a mix of debt and equity purchases) and state backed asset insurance. Our results compute the projected solvency of the banks under a variety of volatility scenarios therefore the value of booked assets in state backed insurance schemes will be the best benchmark for our figures. For banks that have received only capital injections, the value of the implied guarantee on asset values is less clear, nonetheless our results will serve as a useful guide.

We begin by establishing a policy forecast period of one year. We compute the simulations suggested in $\S \S(3.4)$ for a year beginning on April 29, 2009. This exercise is in effect a hindsight approach, given the current 'best' VARMV-GARCH model to April 29, 2009, which provides the anticipated one year spread of equity volatility.

On the basis of these simulations, we compute the asset injections required for each bank under a set of different volatility scenarios. We categorise the range of volatility as 'low', 'medium' and 'high'. Adopting a regulatory target of one standard deviation as the maximum default probability, we compute the required asset injections as a proportion of a bank's balance sheet assets and in terms of trillions of dollars.

The results are presented in Table 4 . The actual dollar asset shortfalls for each bank are presented in columns 5, 6 and 7 for the 'low', 'medium' and 
Table 2 VAR model coefficients from equation 12 for the LCFIs in the sample, for the 'best' model for the year to April 29, 2009. These are the coefficients used in constructing the stress testing and D-to-D forecasts for the sample LCFIs. The standard errors are presented in square brackets. This information is then used to construct the forward-looking simulations and stress tests presented in Table 4, standard errors are presented in square brackets.

\begin{tabular}{|c|c|c|c|c|c|c|c|c|}
\hline & $\mathrm{BOA}$ & $\mathrm{BS}$ & CITI & GS & JPM & LB & ML & MS \\
\hline \multirow[t]{2}{*}{$z_{1,1}$} & -0.0113 & -0.0318 & 0.0375 & -0.0244 & -0.0626 & -0.0657 & 0.0016 & 0.0342 \\
\hline & {$[-0.4236]$} & {$[-0.8225]$} & {$[1.2636]$} & {$[-0.8893]$} & {$[-2.4093]$} & {$[-2.2901]$} & {$[0.0528]$} & {$[1.1777]$} \\
\hline \multirow[t]{2}{*}{$z_{1,2}$} & -0.0254 & 0.0001 & -0.0318 & -0.0643 & -0.0466 & -0.0938 & 0 & -0.0185 \\
\hline & {$[-1.8007]$} & {$[-0.0009]$} & {$[-2.4855]$} & {$[-3.4293]$} & {$[-2.8785]$} & {$[-2.9560]$} & {$[0.0192]$} & {$[-0.8380]$} \\
\hline \multirow[t]{2}{*}{$z_{1,3}$} & -0.0041 & 0.0001 & -0.0076 & -0.0464 & -0.0094 & 0.0743 & 0 & -0.012 \\
\hline & {$[-0.2872]$} & {$[0.0020]$} & {$[-0.4409]$} & {$[-2.4724]$} & {$[-0.5516]$} & {$[1.8530]$} & {$[-0.0136]$} & {$[-0.5116]$} \\
\hline \multirow[t]{2}{*}{$\mu_{1}$} & 0.0002 & 0.0000 & 0.0004 & 0.0006 & 0.0007 & 0.0002 & 0 & 0.001 \\
\hline & {$[0.6588]$} & {$[-0.0392]$} & [1.0349] & {$[1.4241]$} & {$[1.5715]$} & {$[0.2585]$} & {$[-0.0104]$} & [1.8848] \\
\hline \multirow[t]{2}{*}{$z_{2,1}$} & -0.0531 & -0.0212 & -0.0777 & -0.1242 & -0.1627 & 0.0254 & -0.1728 & -0.109 \\
\hline & {$[-2.2633]$} & {$[-0.9547]$} & {$[-3.6325]$} & {$[-4.4690]$} & {$[-6.1065]$} & {$[5.4799]$} & {$[-7.9026]$} & {$[-4.6862]$} \\
\hline \multirow{2}{*}{$z_{2,2}$} & 0.0017 & 0.0338 & 0.0058 & 0.0414 & 0.0018 & 0.0119 & 0.0105 & -0.013 \\
\hline & {$[0.0576]$} & {$[0.9596]$} & {$[0.1761]$} & [1.3895] & {$[0.0631]$} & {$[0.3737]$} & {$[0.3240]$} & {$[-0.3920]$} \\
\hline \multirow[t]{2}{*}{$z_{2,3}$} & 0.3044 & 0.3002 & 0.2871 & 0.2794 & 0.2797 & 0.3213 & 0.2717 & 0.2744 \\
\hline & [9.4887] & [8.2391] & [8.8378] & [10.3164] & {$[9.0040]$} & {$[10.4926]$} & {$[8.6611]$} & [9.3460] \\
\hline \multirow{2}{*}{$\mu_{2}$} & -0.0004 & 0.0003 & -0.0007 & -0.0001 & -0.0003 & -0.0009 & 0.001 & -0.0002 \\
\hline & {$[-0.5762]$} & {$[0.3858]$} & {$[-0.9015]$} & {$[-0.2899]$} & {$[-0.4453]$} & {$[-1.1401]$} & {$[1.2882]$} & {$[-0.3598]$} \\
\hline \multirow[t]{2}{*}{$z_{3,1}$} & -0.0227 & -0.0656 & -0.031 & -0.1158 & -0.0935 & 0.0251 & -0.2067 & -0.0849 \\
\hline & {$[-1.3274]$} & {$[-3.8388]$} & {$[-1.8029]$} & {$[-2.7896]$} & {$[-4.2327]$} & {$[5.9592]$} & {$[-11.094]$} & {$[-4.139]$} \\
\hline \multirow[t]{2}{*}{$z_{3,2}$} & 0.1699 & 0.2249 & 0.1806 & 0.1625 & 0.1897 & 0.1777 & 0.196 & 0.1772 \\
\hline & [8.1896] & [8.3999] & {$[7.8573]$} & {$[5.0805]$} & {$[9.1551]$} & {$[8.7253]$} & {$[7.7854]$} & [8.0724] \\
\hline \multirow[t]{2}{*}{$z_{3,3}$} & 0.0207 & 0.0868 & -0.008 & 0.0592 & -0.0101 & 0.0158 & -0.0516 & 0.0246 \\
\hline & {$[0.7001]$} & {$[2.7802]$} & {$[-0.2678]$} & [1.1994] & {$[-0.3585]$} & {$[0.5181]$} & {$[-1.5831]$} & {$[0.8470]$} \\
\hline \multirow[t]{3}{*}{$\mu_{3}$} & -0.0003 & 0.0001 & -0.0006 & 0.0001 & -0.0005 & -0.0009 & 0.0011 & 0.0001 \\
\hline & {$[-0.4649]$} & {$[0.1077]$} & {$[-0.8248]$} & {$[0.0977]$} & {$[-0.7388]$} & {$[-1.3049]$} & {$[1.2223]$} & {$[-0.1055]$} \\
\hline & SG & BNP & DB & CS & UBS & BARC & HSBC & RBS \\
\hline \multirow[t]{2}{*}{$z_{1,1}$} & 0.1017 & -0.0138 & 0.0305 & 0.0891 & 0.0862 & 0.0048 & -0.0269 & -0.0349 \\
\hline & [3.1936] & {$[-0.4429]$} & [1.0491] & {$[2.8896]$} & {$[2.9669]$} & {$[0.1765]$} & {$[-0.8874]$} & {$[-1.1621]$} \\
\hline \multirow[t]{2}{*}{$z_{1,2}$} & -0.0642 & -0.0716 & -0.0576 & -0.0628 & -0.055 & -0.059 & -0.0178 & -0.076 \\
\hline & {$[-3.5811]$} & {$[-3.7117]$} & {$[-3.4689]$} & {$[-3.7513]$} & {$[-3.1389]$} & {$[-3.1565]$} & {$[-2.2219]$} & {$[-4.8168]$} \\
\hline \multirow[t]{2}{*}{$z_{1,3}$} & -0.008 & 0.0063 & -0.0088 & -0.0104 & -0.0234 & -0.0241 & -0.0152 & 0.0292 \\
\hline & {$[-0.3921]$} & {$[0.2852]$} & {$[-0.4586]$} & {$[-0.5841]$} & {$[-1.1877]$} & {$[-1.0576]$} & {$[-1.4858]$} & [1.4673] \\
\hline \multirow[t]{2}{*}{$\mu_{1}$} & 0.0003 & 0.0008 & 0.0005 & 0.0005 & 0.0002 & 0.0005 & 0.0004 & 0.0009 \\
\hline & {$[0.6782]$} & [1.5088] & [1.0748] & {$[0.9706]$} & {$[0.4751]$} & [1.0103] & {$[1.2968]$} & [1.6641] \\
\hline \multirow[t]{2}{*}{$z_{2,1}$} & -0.0166 & -0.0482 & -0.056 & -0.0695 & -0.0563 & 0.0024 & -0.036 & -0.0002 \\
\hline & {$[-0.5052]$} & {$[-1.3278]$} & {$[-1.6155]$} & {$[-2.0789]$} & {$[-1.9555]$} & {$[0.1182]$} & {$[-0.7244]$} & {$[-0.0096]$} \\
\hline \multirow[t]{2}{*}{$z_{2,2}$} & 0.0304 & 0.0259 & 0.0232 & 0.034 & 0.0113 & 0.0487 & 0.0202 & 0.0136 \\
\hline & {$[0.9312]$} & {$[0.8035]$} & {$[0.7442]$} & [1.0402] & {$[0.3431]$} & {$[1.4997]$} & {$[0.6178]$} & {$[0.4211]$} \\
\hline \multirow[t]{2}{*}{$z_{2,3}$} & 0.262 & 0.2639 & 0.2729 & 0.2667 & 0.2497 & 0.2779 & 0.295 & 0.2683 \\
\hline & [8.2768] & {$[8.4261]$} & {$[8.9700]$} & [8.5673] & {$[8.0932]$} & {$[8.6123]$} & {$[9.5219]$} & [8.3167] \\
\hline \multirow[t]{2}{*}{$\mu_{2}$} & -0.0003 & 0 & -0.0003 & -0.0002 & -0.0005 & -0.0004 & -0.0002 & -0.0007 \\
\hline & {$[-0.4751]$} & {$[-0.0012]$} & {$[-0.4669]$} & {$[-0.3456]$} & {$[-0.6571]$} & {$[-0.5610]$} & {$[-0.2381]$} & {$[-0.8107]$} \\
\hline$z_{3,1}$ & -0.0492 & -0.0558 & -0.0674 & -0.1078 & -0.0563 & -0.0195 & -0.0551 & 0.0001 \\
\hline & {$[-1.691]$} & {$[-1.954]$} & {$[-2.4214]$} & {$[-3.6780]$} & {$[-2.1120]$} & {$[-0.9659]$} & {$[-1.4221]$} & [0.0099] \\
\hline$z_{3,2}$ & 0.191 & 0.1959 & 0.1895 & 0.1806 & 0.1877 & 0.2061 & 0.1892 & 0.1939 \\
\hline & {$[8.1770]$} & {$[8.7984]$} & {$[9.1738]$} & [8.1333] & {$[8.3862]$} & {$[9.0631]$} & {$[7.9232]$} & {$[8.5376]$} \\
\hline$z_{3,3}$ & -0.0187 & -0.0087 & -0.0243 & -0.024 & -0.0202 & -0.0161 & -0.0021 & -0.0001 \\
\hline & {$[-0.6191]$} & {$[-0.2927]$} & {$[-0.8235]$} & {$[-0.8244]$} & {$[-0.6684]$} & {$[-0.5277]$} & {$[-0.0657]$} & {$[-0.0061]$} \\
\hline$\mu_{3}$ & & & -0.0003 & -0.0001 & -0.0003 & -0.0003 & -0.0001 & -0.0003 \\
\hline & [-0.1289] & {$[-0.1046]$} & {$[-0.5257]$} & {$[-0.1985]$} & {$[-0.4215]$} & {$[-0.4229]$} & {$[-0.1319]$} & {$[-0.3982]$} \\
\hline
\end{tabular}


Table 3 Variance model coefficients, for the 'best' MV-GARCH model for each LCFI in the sample as described in equation 14. This model describes the evolution of the conditional covariance in the disturbance process from the VAR model between the LCFI equity returns and the returns on the CDS indices.

\begin{tabular}{|c|c|c|c|c|c|c|c|c|}
\hline & BOA & BS & CITI & GS & JPM & LB & ML & MS \\
\hline \multirow{2}{*}{$k_{1,1}$} & 0.0015 & 0 & 0.0023 & 0.0014 & 0.0014 & 0.0002 & 0 & 0.0021 \\
\hline & {$[8.7168]$} & {$[-0.5360]$} & [13.7300] & {$[5.9156]$} & [6.7041] & {$[0.0298]$} & {$[0.5820]$} & [7.6889] \\
\hline \multirow[t]{2}{*}{$k_{1,2}$} & -0.0002 & 0.0026 & -0.0001 & 0.0033 & -0.0005 & 0.003 & -0.0035 & -0.0004 \\
\hline & {$[-0.3719]$} & {$[0.0895]$} & {$[-0.1828]$} & [7.1179] & {$[-0.7325]$} & {$[0.0292]$} & {$[-0.1332]$} & {$[-0.7655]$} \\
\hline \multirow[t]{2}{*}{$k_{1,3}$} & 0 & 0.0003 & 0.0003 & 0.0026 & 0 & 0.0039 & -0.0013 & 0.0004 \\
\hline & {$[0.0605]$} & {$[0.0024]$} & {$[0.7257]$} & [1.6912] & {$[-0.0958]$} & {$[0.0300]$} & {$[-0.0176]$} & {$[0.8850]$} \\
\hline \multirow[t]{2}{*}{$k_{2,2}$} & 0.0043 & 0.0019 & 0.0042 & 0.0007 & 0.0041 & 0.0028 & 0.0004 & 0.0043 \\
\hline & [11.8982] & {$[0.0510]$} & [12.0833] & {$[0.4224]$} & [11.7785] & {$[0.0261]$} & {$[0.0019]$} & [11.6282] \\
\hline \multirow{2}{*}{$k_{2,3}$} & 0.002 & 0.0014 & 0.0024 & 0.0089 & 0.002 & -0.0012 & 0.0041 & 0.0022 \\
\hline & [5.8932] & {$[0.0076]$} & {$[8.3134]$} & {$[0.4646]$} & {$[5.4553]$} & {$[-0.0039]$} & {$[0.0028]$} & [5.7262] \\
\hline \multirow{2}{*}{$k_{3,3}$} & 0.0035 & 0.0008 & -0.0035 & 0 & -0.0034 & 0 & 0.0011 & -0.0037 \\
\hline & {$[12.582]$} & {$[0.0032]$} & {$[-12.949]$} & {$[-0.000]$} & {$[-11.789]$} & {$[0.000]$} & {$[0.000]$} & {$[-11.854]$} \\
\hline \multirow[t]{2}{*}{$A_{1}$} & 0.35 & 0.8178 & 0.4219 & 0.2584 & 0.2729 & 0.4538 & 0.7077 & 0.2849 \\
\hline & {$[22.5452]$} & [81.1842] & [20.8889] & [19.8571] & [20.4104] & {$[30.8470]$} & [61.9968] & [21.8299] \\
\hline \multirow[t]{2}{*}{$A_{2}$} & 0.2603 & 0.1882 & 0.2529 & 0.3318 & 0.2494 & 0.2912 & 0.259 & 0.2605 \\
\hline & [16.7437] & [16.6667] & [17.4033] & [19.2090] & {$[16.6432]$} & [15.5988] & [14.8741] & [17.1981] \\
\hline \multirow[t]{2}{*}{$A_{3}$} & 0.3152 & 0.0844 & 0.2526 & 0.4145 & 0.3356 & 0.3033 & 0.2829 & 0.3399 \\
\hline & {$[19.7256]$} & [10.4001] & {$[17.7373]$} & [10.1469] & [21.9345] & [15.8910] & [14.2168] & [19.6893] \\
\hline \multirow[t]{2}{*}{$B_{1,1}$} & 0.9427 & 0.7934 & 0.915 & 0.9657 & 0.9634 & 0.9474 & 0.8076 & 0.9603 \\
\hline & [210.1620] & [3498.8957] & [137.5982] & [348.5225] & [311.4317] & [392.6591] & [1942.0523] & [287.4377] \\
\hline \multirow[t]{2}{*}{$B_{2,2}$} & 0.9608 & 0.9817 & 0.9631 & 0.9449 & 0.963 & 0.9558 & 0.9663 & 0.9606 \\
\hline & [236.0391] & {$[578.0862]$} & [261.2307] & [198.0115] & [249.8207] & [196.1223] & [259.3536] & [241.2347] \\
\hline \multirow{3}{*}{$B_{3,3}$} & 0.9452 & 0.9968 & 0.9599 & 0.919 & 0.9401 & 0.9481 & 0.9583 & 0.9373 \\
\hline & [165.8104] & [1671.9791] & [236.6457] & [65.0249] & [160.0957] & [151.3784] & [168.1619] & [145.9701] \\
\hline & SG & BNP & DB & $\mathrm{CS}$ & UBS & BARC & HSBC & RBS \\
\hline \multirow[t]{2}{*}{$k_{1,1}$} & 0.0027 & 0.0025 & 0.002 & 0.0025 & 0.0017 & 0.002 & -0.0001 & 0.003 \\
\hline & {$[7.7069]$} & [7.1997] & [8.6885] & {$[7.5796]$} & {$[6.7697]$} & {$[6.7754]$} & {$[-0.1188]$} & [11.7987] \\
\hline \multirow[t]{2}{*}{$k_{1,2}$} & -0.0011 & -0.0011 & -0.0009 & -0.0015 & -0.0009 & -0.0008 & 0.0026 & -0.0015 \\
\hline & {$[-2.1564]$} & {$[-2.4321]$} & {$[-1.6446]$} & {$[-3.0490]$} & {$[-1.3696]$} & {$[-1.6578]$} & {$[0.1171]$} & {$[-2.5886]$} \\
\hline \multirow[t]{2}{*}{$k_{1,3}$} & -0.0009 & -0.0008 & -0.0004 & -0.0004 & -0.0005 & -0.0005 & 0.005 & -0.0013 \\
\hline & {$[-1.7587]$} & {$[-1.6363]$} & {$[-0.9367]$} & {$[-0.8357]$} & {$[-1.0657]$} & {$[-0.8424]$} & {$[0.1207]$} & {$[-1.9268]$} \\
\hline \multirow[t]{2}{*}{$k_{2,2}$} & 0.0041 & 0.004 & 0.0042 & 0.0041 & 0.0042 & 0.0042 & -0.0037 & 0.0038 \\
\hline & [10.5663] & [11.2480] & [11.2697] & [10.4623] & [11.7192] & [11.6208] & {$[-0.2266]$} & [11.0338] \\
\hline \multirow[t]{2}{*}{$k_{2,3}$} & 0.0016 & 0.0016 & 0.0017 & 0.0018 & 0.0017 & 0.002 & 0.0002 & 0.0015 \\
\hline & {$[4.9476]$} & {$[4.9615]$} & {$[5.0011]$} & {$[5.3294]$} & [4.9811] & {$[5.8228]$} & {$[0.0039]$} & [3.8540] \\
\hline \multirow[t]{2}{*}{$k_{3,3}$} & 0.0033 & 0.0033 & 0.0036 & 0.0034 & 0.0034 & 0.0035 & 0 & 0.0033 \\
\hline & [12.380] & [12.243] & {$[12.346]$} & [11.834] & {$[12.501]$} & {$[12.770]$} & {$[-0.000]$} & [12.101] \\
\hline \multirow[t]{2}{*}{$A_{1}$} & 0.3504 & 0.2747 & 0.2911 & 0.334 & 0.2643 & 0.3206 & 0.3359 & 0.5181 \\
\hline & [19.9274] & [14.7010] & [21.5320] & [18.7879] & [16.9423] & [24.3199] & [22.9355] & [46.2015] \\
\hline \multirow[t]{2}{*}{$A_{2}$} & 0.2642 & 0.2525 & 0.2767 & 0.2623 & 0.2704 & 0.2549 & 0.2465 & 0.2528 \\
\hline & [15.8140] & [15.6025] & [17.4513] & [15.8295] & {$[15.7396]$} & [14.6751] & [15.1470] & [16.9238] \\
\hline$A_{3}$ & 0.2956 & 0.3034 & 0.3158 & 0.2929 & 0.3111 & 0.2938 & 0.3405 & 0.2706 \\
\hline & [18.4202] & [18.1029] & [18.6393] & [17.0637] & [18.0399] & [17.3355] & [16.7938] & [17.4146] \\
\hline$B_{1,1}$ & 0.9391 & 0.9594 & 0.9568 & 0.9425 & 0.9656 & 0.9515 & 0.9533 & 0.8903 \\
\hline & [183.1192] & [175.9423] & [259.8678] & [157.8795] & [251.3334] & [281.5061] & {$[240.4076]$} & [145.0429] \\
\hline$B_{2,2}$ & 0.9591 & 0.9616 & 0.9559 & 0.9584 & 0.9571 & 0.9613 & 0.9633 & 0.963 \\
\hline & [212.5441] & [223.8041] & [208.2144] & [207.0664] & [203.9593] & [215.0648] & [234.2748] & [267.6662] \\
\hline$B_{3,3}$ & 0.952 & 0.9494 & 0.945 & 0.9519 & 0.9469 & 0.951 & 0.9376 & 0.958 \\
\hline & [184.9690] & [171.0815] & [159.9146] & [174.2307] & [162.6896] & [171.8329] & [126.8111] & [217.2194] \\
\hline
\end{tabular}


'high' volatility scenarios, respectively. Columns 2, 3 and 4 present the asset shortfalls divided by the average level of imputed assets for the three months to July 31, 2007. This denotes the pre-crisis solvency adjustment by the bank.

A shown in table 4, an emerging striking feature is that, even under 'low' volatile scenarios, only two banks were not in need of additional capital injections and asset insurance the imputed aggregate capital requirements were approximately $\$ 2.16 \mathrm{tr}$. This amount would have risen to $\$ 3.82 \mathrm{tr}$ and $\$ 5.7 \mathrm{tr}$ respectively under less benign volatility profiles.

Specifically for the UK LCFIs, the relevant figures are $\$ 0.55 \mathrm{tr}, \$ 0.95 \mathrm{tr}$, $\$ 1.38$ tr. Although the estimated capital injections are calculated under an assumed maximum distance to default of one standard deviation, the results provide ground for an informal comparison between our estimates and the official recapitalization schemes of distressed banks. In particular, since the onset of the financial crisis, Royal Bank of Scotland (RBS) received direct government support in various forms in excess of GBP350bn, most of this support has been in the form of asset insurance provided by membership of the UK Asset Protection Agency (APA). ${ }^{3}$ An important observation is that under a scenario of high asset volatility, our model estimates appear in line with the actual recapitalization arrangements.

In the US the most obvious examples of recapitalization recipients via public funds were Citi and Bank of America. Citi placed in the troubled asset relief program (TARP) assets valued at $\$ 300 \mathrm{bn}$ and received an additional $\$ 45 \mathrm{bn}$ as preferred stock from the US Treasury. As is evident from our simulations, Citi would have needed an additional amount of capital of $(\$ 0.266 \mathrm{tr}$ to $\$ 0.522 \operatorname{tr}$ ) under a projected low-medium volatility regime. Bank of America placed $\$ 118 \mathrm{bn}$ in the asset guarantee scheme and received $\$ 45 \mathrm{bn}$ in preferred stock investments. The remaining banks received indirect support from the US government as it stepped up efforts to mitigate systemic counterparty risks, thus ensuring that individual institutions were adequately capitalised and individually capable of surviving reasonable stress events. For instance, during the financial crisis, the Federal Reserve introduced a number of short-term credit and liquidity facilities to help stabilise markets. Some of the transactions under these facilities provided liquidity to institutions whose disorderly failure could have severely stressed an already fragile financial system. Goldman Sachs was one of the heaviest users of these loan facilities, taking out numerous loans from March 18, 2008 to April 22, 2009.

On balance, the 'projected' recapitalization needs for all the European LCFIs range between $\$ .35$ tr and $\$ .78$ tr. As a proportion of their assets, the required additional assets (in the form of capital and asset insurance) varied from an average low of $7 \%$ to an average high of $22 \%$ depending upon the realized volatility profile. Interestingly, we can see that in comparison with their European-based counterparties, for a large number of US LCFIs, the supplemental asset infusions were well in excess of $10 \%$. Under deteriorating

\footnotetext{
3 Source: HM Treasury Publications, December 2009, 'Royal Bank of Scotland: details of Asset Protection Scheme and launch of the Asset Protection Agency'.
} 


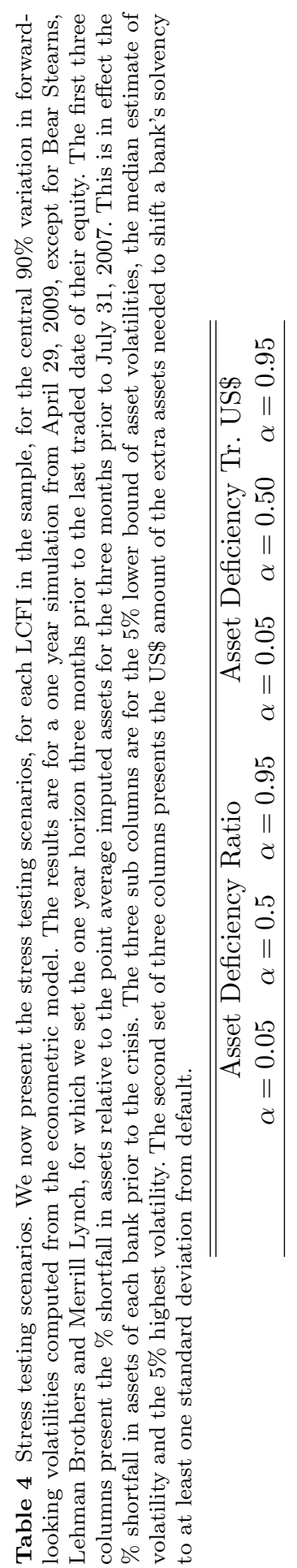

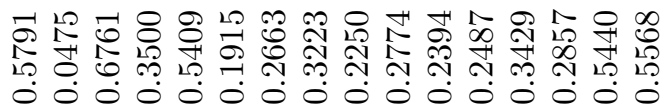

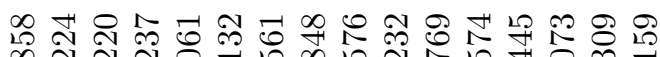

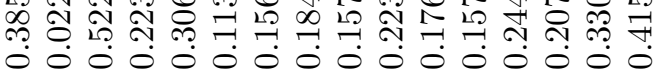

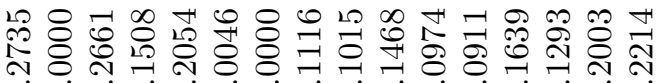

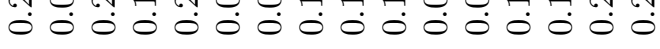

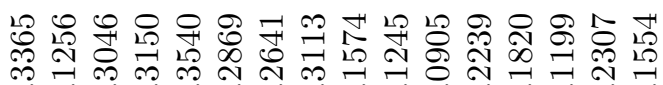

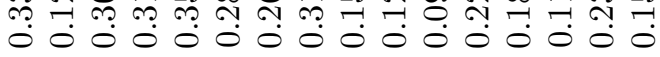

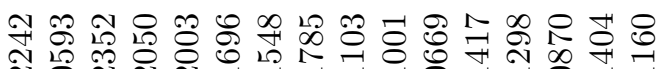

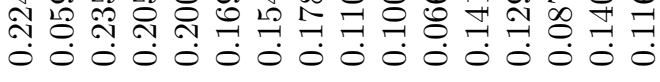

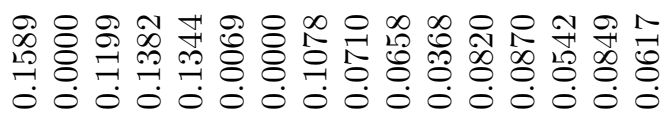

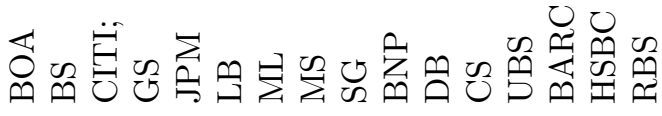




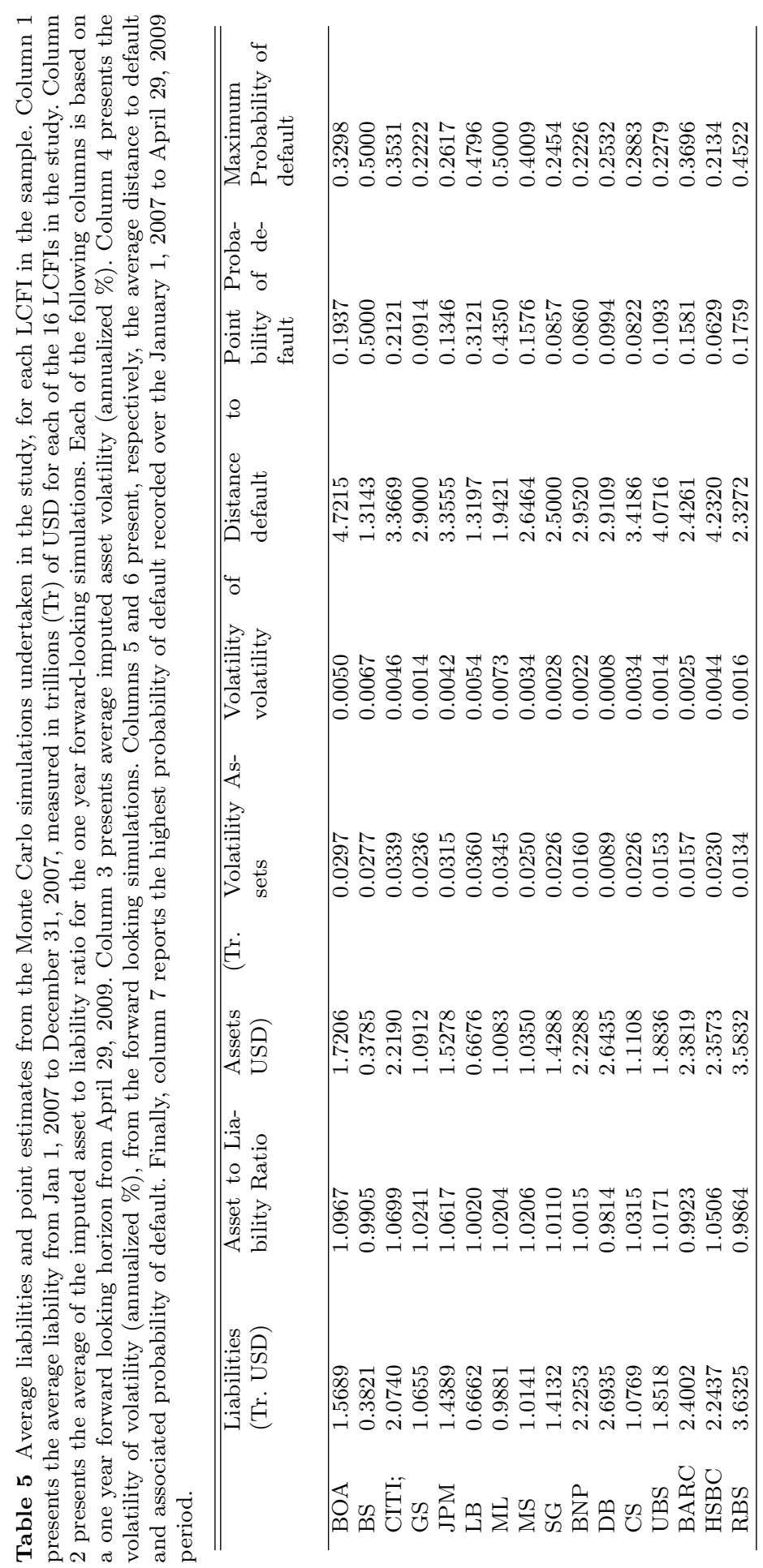


asset volatility scenarios, these amounts increased very rapidly and more significantly for the US LCFIs. Moreover, during periods of high asset volatility (July 2007) the average injections required as a proportion of assets rose to $28 \%$, well in excess of their UK and European counterparties for which the equivalent measures were $13 \%$ and $15 \%$, respectively.

Overall, our results indicate an elevated degree of fragility for the LCFIs, with total assets in excess of $\$ 27 \mathrm{tr}$ and liabilities of $\$ 26.7 \mathrm{tr}$. Furthermore, these banks would have been vulnerable even under favourable volatility scenarios, thereby requiring substantial capital injections and asset insurance to restore them to financial health.

Table 5 presents the computed estimates from the simulations for the asset values, the default probabilities and the resulting D-to-D for all the 16 LCFIs over the one year forecasting period. Liabilities are kept at their 2007 level. It is worth noting that the resulting asset to liabilities ratios for four banks were below unity. Additionally, the estimated conditional asset volatility for the US banks was substantially higher, at 3\% compared with $1.7 \%$ for the UK and European banks. More importantly, the volatility of volatility was almost double in magnitude: $0.4 \%$ to $2.3 \%$.

To the extent that the D-to-D is an adequate proxy of banking fragility, our results suggest that the average D-to-D was only 2.9 standard deviations. For three US LCFIs, the D-to-D was below 2 and the associated default probabilities were the highest in the group. Not surprisingly, these LCFIs were Bear Stearns, Lehman Brothers and Merrill Lynch, none of which were able to survive the global financial crisis.

Notably, RBS was one of the most severely affected institutions during the financial crisis. The take over of ABN-Amro in 2007, in addition to other acquisitions over the preceding decade, had resulted in a rapid increase in the total debt liabilities of the bank, which are in fact the largest in our sample, as of July 31,2007 . Note that, over our stress testing period, the asset to liability ratio of the bank surged to $98 \%$ (i.e. an insolvent state). It appears also that Deutsche Bank was a further example of LCFI with a similar low asset to liability profile. However, the point asset volatility and volatility of volatility were substantially lower (in addition to having a far lower aggregate debt). Therefore, Deutsche Bank appeared less vulnerable to shocks than RBS.

Within the cluster of non-US institutions, RBS had the highest average probability of default, at a level of $17 \%$ compared to the non-US average of $10 \%$. Furthermore, the maximum probability of default $(47 \%)$ was the fourth highest in the sample, immediately below Bear Stearns, Lehman Brothers and Merrill Lynch.

Taken together, our results are are indicative of the types of transmission mechanisms discussed in $\S(2)$. Illustrating some of the fragility within the international financial system. The group of LCFIs in our sample have with asset/liability values well in excess of about two times the annual GDP of the US economy. 
In summary, the conditional volatility of banks' assets, calculated using the first and second moments of the indices in the CDS index markets, provide a number of interesting insights into the important issue of default risk.

\section{Concluding Remarks}

Bank default risk is currently the predominant issue of concern to academics, financial practitioners and policymakers across the world. The recent failure of several LCFIs illustrates that the too big to fail paradigm predominant in the analysis of financial stability of large mainstream commercial and investment banks is no longer valid. We approach the issue of the stability of the banking sector by studying the potential statistical relationships between the moments of the CDS indices the equity of LFCIs.

In this paper, we propose a set of models and empirical tests for predicting the current and simulated correlative relationships between CDS markets and a number of systemically important financial institutions. Specifically, we jointly model the evolution of equity returns and asset return volatility of 16 LCFIs, using a VAR-MV-GARCH model, with the evolution of two standardised CDS indices. The conditional equity volatilities are used to impute the value and volatility of assets using a Merton type model.

The estimated conditional covariance of he CDS market and LCFI asset volatility is captured by the evolution of the investment-grade CDX NorthAmerican and the iTraxx Europe indices with LCFI equity. The multivariate GARCH model is then used to construct forecasts of future volatility conditioned on the co-evolution of the equity returns and the CDS market. The econometric framework allows for testing of the predictive contribution of developments in the CDS market on the stability of the banking sector as depicted by the D-to-D of major financial institutions.

We conclude that there is evidence of correlative relationships between the equity volatility of LCFIs and the volatility of the CDS index market matters during the crisis period. In the presence of increasing asset volatility, financial institutions would require fresh capital injections and additional assets entering insurance programs such as TARP and the UK APA. We view these results as encouraging for the methodology, and we hope that the approach we take will be useful in future explorations.

A caveat of the methodology used in this paper is that our calculations are based on the assumption that the value of liabilities is known. Therefore, the safety and soundness of each particular institution is a function of the market value of the assets. Future research should relax this assumption and allow for the stochastic fluctuation of the value of the liabilities and its possible relationship with the value of assets. An additional innovation could be the adoption of pareto-stable distributions in place of the normal distribution, which is commonly believed to underestimate the true frequency of extreme observations. 


\section{References}

Allen, F. and E. Carletti (2006). Credit risk transfer and contagion. Journal of Monetary Economics 53(1), 80-111.

Allen, F. and D. Gale (2000). Financial contagion. Journal of Political Economy $108(1), 1-33$.

Baur, D. and E. Joossens (2006). The effect of credit risk transfer on financial stability. Technical Report 21521, EUR Working Paper Series.

Behr, P., R. Schmidt, and R. Xie (2010). Market structure, capital regulation and bank risk taking. Journal of Financial Services Research 37, 131-158. 10.1007/s10693-009-0054-y.

Berger, A., R. DeYoung, M. Flannery, D. Lee, and O. Öztekin (2008). How do large banking organizations manage their capital ratios? Journal of Financial Services Research 34, 123-149. 10.1007/s10693-008-0044-5.

Berndt, A., R. Douglas, D. Duffie, M. Ferguson, and D. Schranz (2005). Measuring default risk premia from default swap rates and EDFs. Technical Report 173, BIS Working Papers.

Bystrom, H. N. E. (2005). Credit default swaps and equity prices: The iTraxx CDS index market. Lund University Working Paper Series.

Diebold, F. X. and R. S. Mariano (1995). Comparing predictive accuracy. Journal of Business \& Economic Statistics 13(3), 253-63.

Duffie, D. (2008). Innovations in credit risk transfer: Implications for financial stability.

Giacomini, R. and B. Rossi (2009). Detecting and predicting forecast breakdowns. Review of Economic Studies 76(2), 669-705.

Goldsmith-Pinkham, P. and T. Yorulmazer (2010). Liquidity, bank runs, and bailouts: Spillover effects during the northern rock episode. Journal of Financial Services Research 37, 83-98. 10.1007/s10693-009-0079-2.

Gropp, R., J. Vesala, and G. Vulpes (2006). Equity and bond market signals as leading indicators of bank fragility. Journal of Money, Credit and Banking 38(2), 399-428.

Hafner, C. M. (2003). Fourth moment structure of multivariate garch models. Journal of Financial Econometrics 1(1), 26-54.

Hawkesby, C., I. W. Marsh, and I. Stevens (2003). Comovements in the prices of securities issued by large complex financial institutions. Technical report, Bank of England: Financial Stability Review: Dec 2003.

$\mathrm{Hu}$, H. T. C. and B. Black (2008). Debt, equity, and hybrid decoupling: Governance and systemic risk implications. European Financial Management 14(4), 663-709.

Jorion, P. and G. Zhang (2007). Good and bad credit contagion: Evidence from credit default swaps. Journal of Financial Economics 84(3), 860-883.

Lehar, A. (2005). Measuring systematic risk: A risk management approach. Journal of Banking and Finance 29(10), 2577-2603.

Longstaff, F. A. (2010). The subprime credit crisis and contagion in financial markets. Journal of Financial Economics 97(3), 436 - 450. 
Longstaff, F. A., S. Mithal, and E. Neis (2005). Corporate yield spreads: Default risk or liquidity? new evidence from the credit default swap market. Journal of Finance 60(5), 2213-2253.

Merton, R. C. (1974a). On the pricing of corporate debt: The risk structure of interest rates. Journal of Finance 29(2), 449-70.

Merton, R. C. (1974b). Theory of rational option pricing. Bell Journal of Economics 4(1), 141-83.

Morrison, A. D. (2005). Credit derivatives, disintermediation, and investment decisions. Journal of Business 78(2), 621-648.

Sy, A. N. R. and J. A. Chan-Lau (2006). Distance-to-default in banking: A bridge too far? IMF Working Papers 06/215, International Monetary Fund.

Wagner, W. and I. Marsh (2006). Credit risk transfer and financial sector stability. Journal of Financial Stability 2(2), 173-193.

Williams, J. and C. Ioannidis (2011). Multivariate asset price dynamics with stochastic covariation. Quantitative Finance 11(1), 125-134.

Zhu, H. (2006). An empirical comparison of credit spreads between the bond market and the credit default swap market. Journal of Financial Services Research 29(3), 211-235. 